\title{
Can Marketization Improve Sustainable Development in Northeastern China? Evidence from the Perspective of Coupling Coordination Degree Model
}

\author{
Sai Tang $\mathbb{D}^{1},{ }^{1}$ Yue Zhu $\mathbb{D}^{,},{ }^{2}$ Fang Wang $\mathbb{D}^{3},{ }^{3}$ and Na Shen $\mathbb{D}^{4}$ \\ ${ }^{1}$ School of Humanities, Social Sciences \& Law, Harbin Institute of Technology, Harbin, China \\ ${ }^{2}$ School of Management, Harbin Institute of Technology, Harbin, China \\ ${ }^{3}$ Beijing Laboratory of National Economic Security Early-warning Engineering, Beijing, China \\ ${ }^{4}$ Institute for Information Processing Technologies, Karlsruhe Institute of Technology, Karlsruhe, Germany
}

Correspondence should be addressed to Yue Zhu; zhuyue@hit.edu.cn

Received 18 April 2021; Revised 13 October 2021; Accepted 16 December 2021; Published 4 January 2022

Academic Editor: Haoran Zhang

Copyright ( $\odot 2022$ Sai Tang et al. This is an open access article distributed under the Creative Commons Attribution License, which permits unrestricted use, distribution, and reproduction in any medium, provided the original work is properly cited.

\begin{abstract}
With the acquisition of sustainable development, pursuing the coordinated development of social economy and ecological environment has been a critical approach of Northeastern China. Since the reform and opening-up, marketization has profoundly affected the regional social economy. However, what role will marketization play in regional sustainable development? Can marketization improve sustainable development measured by the coupling coordination degree? This paper adopts the coupling coordination degree model (CCDM) to estimate the coupling coordination degree and further explore the impact of marketization on the coupling coordination degree in Northeastern China from 1994 to 2019. The results show that the average values of the static coupling degree (SCD), dynamic coupling degree (DCD), and coupling coordination degree (CCD) remained in a tiny coordinated state, which indicated that the level of sustainable development in Northeastern China is presented still primary from 1990 to 2019. Marketization has a significant negative impact on the coupling coordination degree, which indicates that marketization should be considered in the process of sustainable development in Northeastern China.
\end{abstract}

\section{Introduction}

To achieve the target China announced in December 2020 that to be carbon-neutral by 2060 , improving sustainable development in regions demonstrated fundamental for economic growth and carbon emission reduction [1-4]. As the second largest economy and largest carbon emitter now, China experienced rapid development since the reform and opening-up in 1978. During the transition from a planned economy to a market economy over 40 years, regions in China unleashed significant vitality in economic growth and social construction. Various researchers believe that marketization is revealed to be a key role in driving economic growth and brings phenomenal achievements in socialeconomic development in China [5-7]. However, China's situation of rapid economic growth revealed to be changed into a new normal characterized by medium-speed growth after reaching its pinnacle in 2010. Meanwhile, economic growth in regions of China is revealed to be accompanied by a myriad of environmental problems, which threatens to reduce regions' ability to achieve sustainable development. Therefore, during the new normal, improving sustainable development to tackle the pressure of social-economic growth and carbon emission reduction is a key and urgent issue in China.

Sustainable development refers to the consistent development and harmony between social economy and ecological environment in regions' systems. Many methods have been developed to measure the situation of sustainable development, e.g., the coupling coordination degree model (CCDM), the Pressure-State-Response model (PSR), the system dynamics model (SD), the logarithmic mean divisia index decomposition model (LMDI), etc. Among them, the coupling coordination degree model is revealed to be one of 
the most widely used due to the fact that CCDM measures both the levels of development and the complex interactions between different subsystems, e.g., the subsystem of social economy and ecological environment, which reflects the concept of harmony and unity between human activities and ecological environment in sustainable development $[8,9]$. Because social economy (SE) and ecological environment (EE) reflect the two important aspects of economic growth and emission reduction targeting sustainable development, regarding the CCDM model, coupling measures the degree of interaction between the subsystems of SE and EE. Coordination describes the level of coordinated development among various elements of the sustainable system. The CCDM model is well applied in analyzing the relationship of $\mathrm{SE}$ and $\mathrm{EE}$ within various researches $[8,10,11]$. Most scholars claimed that, with the rapid growth of the social economy in China, the total coupling coordination degree of SE and EE was revealed to be relatively sound coordinated, in which the marketization reform played a key role in driving high-speed economic growth. However, few researches link marketization and the coupling coordination degree. Whether marketization can improve sustainable development, i.e., the coupling coordination degree, still remains to be explored.

As a prior study claimed, marketization drove the significant improvement in economic growth in China. However, meanwhile, marketization left an imbalance in social-economic development among different regions (i.e., Eastern China, Central China, Western China, Northeastern China). In contrast with that in the early 1960s, the social economy in Northeastern China suffers the pressure of decline and backward in recent times, either does the ecological environment suffer from deterioration. Due to the fact that the marketization reform in China is manifested as gradualness, there exists an imbalance of the marketization process among different regions in China. According to the research by Fan et al. [12], as an inland region and the most farreaching region affected by the planned economy, Northeastern China suffers the lowest degree of marketization among four regions of China, which may lead to the backward level of social economy and ecological environment. Therefore, under the policy priority of the new revitalization of the old industrial base in Northeastern China, marketization plays a significant role in promoting sustainable development. However, is marketization a bottleneck or propeller for improving the comprehensive level of the social economy and the ecological environment in Northeastern China? Can marketization drive sustainable development in Northeastern China by boosting the coupling coordination degree? This paper focuses on exploring the relationship of marketization and the coupling coordination degree in Northeastern China in order to explain the above questions, which is hoped to provide assistance in realizing future sustainable development in Northeastern China.

The novelty of this study is reflected as linking the marketization degree and the coupling coordination degree in such a backward region as Northeastern China. Most existing literature only links marketization and economic growth and demonstrates the significant positive role marketization plays in economic catch-up in backward regions. Various scholars hold that marketization boosts economic growth by advancing the allocation efficiency of production factors and saving endogenous transaction costs $[5,6,13]$. However, marketization will simultaneously provide a nonnegligible impact on the system of the ecological environment by advancing pollution emission reduction technologies. Thus, how marketization will affect the two systems of SE and EE and their interaction relationship should be explored further. In order to investigate the relationship between marketization and the sustainable development (coupling coordination degree of SE and $\mathrm{EE}$ ) in Northeastern China, this paper first adopts the coupling coordination degree model (CCDM) to estimate the coupling coordination relations between SE and EE in Northeastern China, which reflects the level of sustainable development. Moreover, on the basis of market theory, we introduce the comprehensive level of marketization as an independent variable that may have an influence on the coupling coordination degree (CCD) of SE and EE to further clarify the impact of marketization on CCD through an autoregressive moving average model with a fixed effect. Our empirical findings will be expected to provide policy reference for low-carbon transformation in Northeastern China.

The remainder of this paper is structured as follows. In the second part, we give a view of the literature within the area of measurement of sustainable development from a coordinated view as well as the area of marketization. In the third part, we focus on methodology, the steps of establishing the coupling coordination degree model, and the comprehensive index system of SE and EE. The result of empirical analysis is revealed and discussed in the fourth part. In the fifth part, we focus on the empirical analysis of the impact of marketization degree on the CCD in Northeastern China to clarify the core scientific issue that what role marketization plays in the coordination of SE and EE. Finally, the sixth part is devoted to some concluding comments and policy suggestions.

\section{Literature Review}

2.1. Measurement of Sustainable Development from the View of Coupling Coordination. Over the past few decades, numerous scholars have researched the mutual relation between $\mathrm{SE}$ and $\mathrm{EE}$ in order to measure sustainable development. Due to different research perspectives, a majority of scholars applied different methods including the Environmental Kuznets Curve, the green efficiency model, and the coupling coordination degree model on the quantized measurement of sustainable development [14-18]. The Environmental Kuznets Curve (EKC) represented as follows posits the inverted $U$-shaped relation where the environmental quality declines initially and improves after the inflection point with the growth of economic income between environmental quality and economic income [19].

$$
z=m-n(x-p)^{2}
$$


where $z$ is the degree of eco-environment degradation, $x$ is the level of per capita income, $m$ is the environmental threshold $(m>0)$, and $n$ and $p$ are nondeterministic parameters that are nonnegative. The existence of the U-shape relation implied that the coupling state between SE and EE could be quantified by determining the distribution at any economic development level. On the basis of the total factor productivity (TFP), Huang et al. [20] defined the green efficiency measured by data envelopment analysis (DEA) based on a slack variable (SBM) as the input-output efficiency under the constraint of resources and environment, which treated resources as the input, economic development as the "good" output, and environmental pollution as the "bad" output of the system. The coupling state is dependent on the value of green efficiency which is proportional. Another model that assesses the reciprocal relation between $\mathrm{SE}$ and $\mathrm{EE}$ is the coupling coordination degree model (CCDM) derived from the physical coupling theory. Coupling, which is a phenomenon in which system elements influence each other through various interactions, originates from the system multiobjective decision analysis that is described as follows. Assume that there are $K$ goals in system $f_{i}(x)(i=1,2, \ldots, K)$ including $K_{1}$ goals where target values are expected to be maximum, $K_{2}$ goals where target values are expected to be minimum, and $K-K_{1}-K_{2}$ goals where target values are expected to be the closest to a certain value. Assume $d_{t}$ as the efficacy functions of the goals above measuring the satisfaction degree, which is valued as follows: if the target values achieve the best satisfaction, $d_{t}=1$; if the target values gain the worst satisfaction, $d_{t}=0$. The total desirability functions $C=C\left(d_{1} d_{2} \ldots d_{k}\right) ; \quad 0 \leq C \leq 1$ is established as the coupling degree in which the value is proportional to the coupling relation between different systems.

In terms of the three models quantifying the relationship between SE and EE to measure sustainable development, there are existent limits in the application. Within the Environmental Kuznets Curve, the inverted U-shaped relation between economy and environment can be reflected, but the proxy indicator of economic development is generally adopted as regional GDP, which cannot summarize the complexity of economic subsystems. In addition, with the weak indicators adopted measuring the economic subsystem, it is difficult to assess the coupling relation between economic and environmental subsystems through the EKC model. Similarly, the measure index adopted in the green efficiency model biases toward the system input, which lacks an index reflecting systematic structure and function. Although the degree of coordinated development is revealed through the value of green efficiency, the current corresponding stage cannot be determined [21]. By contrast, within the coupling coordination degree model, characteristics of economic and environmental subsystems can be fully reflected. The coupling relation between regional economy and environment is quantified as well as the current corresponding stage, which can satisfy the dynamic needs of coordinated measurement. Existing studies believe that coupling coordination is one of the basic principles of sustainable development due to the fact that sustainable development emphasizes coordinated development between $\mathrm{SE}$ and $\mathrm{EE}$ in the process of social-economic growth. Therefore, the coupling theory becomes one of the most widely used perspectives to measure sustainable development.

2.2. Impact of Marketization on SE and EE. Through the historical practice of economic transition in Eastern Europe and the former USSR in the 1990s, the influence of marketization on SE and EE has been extensively studied. A majority of scholars have focused on issues such as the mechanism that marketization affected economic growth, and the "breaking institutional change" which North [22] defined produced by marketization. In terms of the connotation of marketization, due to the fact that economic transition only occurred in Eastern Europe, USSR, China, and other countries, marketization exhibits typical regional characteristics differing from western governments' repairing to market system. In China, current comprehension from previous literature in terms of the connotation of marketization is mainly divided into two approaches. One approach regarded marketization as a process by measuring the effect of the transformation from the planned economy system to the market system [23]. Another approach regarded marketization as a result by measuring the gap between the current market system and the standard market system [24]. In terms of the quantitative index of marketization, the current widely accepted index by academic cycles included the transformation index in the Transition Report of the European Bank for reconstruction and development (EBRD) which scored the dimensions of price liberalization, enterprise reform, privatization, foreign exchange and foreign trade liberalization, competitive policies and financial institution reform, the market system index established by Fan et al. [23] which assessed the process of marketization reform with China as a research sample, and the Beijing Normal University Index which focused on examination and qualification of results by market reform.

In terms of the mechanism that marketization affects SE and $\mathrm{EE}$, the perspective of regarding marketization as a mode of resource allocation which could promote the improvement of total factor productivity through the improved resource allocation efficiency was generally accepted by academic circles. In the economic field, pollution is restricted by economic laws as economic behavior. Due to market failures, the costs and benefits of economic activities would be reflected by wrong information about resource scarcity instead of by prices, resulting in the imbalance of economic and environmental subsystems.

To sum up, regarding the core scientific issue that how marketization would affect sustainable development, existing literature focused on how to measure sustainable development from the perspective of coupling coordination and the impact of marketization on SE and EE [8-11]. Regarding the measurement of sustainable development, most researches provided a significant method system of CCDM to quantify the coordination development of SE and EE, which contributes the key methodology to our study. On 
the other hand, regarding the impact of marketization, various previous researches led to the conclusion that marketization could promote economic growth and reduce environmental pollution by optimization of resource allocation $[5-7,13]$. However, realistic condition in Northeastern China is manifested as the slow process of marketization and low external dependence degree. Therefore, it is inappropriate to compare marketization in Northeastern China with the standard market system instead of regarding marketization as a process influencing SE and EE. Therefore, we adopt Fan's definition of marketization as a process taking Northeastern China as a research sample. In addition, a majority of the existing research focused on the influence of marketization only on economic system, which ignored the influence of marketization on the coordinated relation between SE and EE. We attempt to introduce the variable of marketization to clarify the impact of on marketization coordinated relation between SE and EE in Northeastern China, which is expected to provide a reference for future low-carbon transition of resource-based regions.

\section{Methodology}

The coupling coordination degree model, which originates from system coupling analysis, is currently widely in the quantitative evaluation of sustainable development and the reciprocal relation between $\mathrm{SE}$ and $\mathrm{EE}$ subsystems. According to the coupling theory, the steps to establish the coupling coordination degree model can be lined as indicator system construction, data normalization, evaluation of the subsystems, calculation of coupling degree, and calculation of the degree of coupling coordination.

3.1. Indicator System Construction. Drawn from Tan and Lu [25], we construct the evaluating indicator system of the social economy subsystem and the ecological environment subsystem, as shown in Table 1. Data of the indicators are collected from the China Statistical Yearbook, China Labor Statistics Yearbook, and the Statistical Yearbook of Liaoning province, Jilin province, and Heilongjiang province.

3.2. Data Normalization. In SE and EE subsystems, we suppose $X_{i}$ as the dataset of the SE subsystem indicators $\left\{x_{1}, x_{2}, \ldots, x_{i}\right\}$ and $Y_{j}$ as the dataset of the EE subsystem indicators $\left\{Y_{1}, Y_{2}, \ldots, Y_{j}\right\}$. Due to different dimensions in the indicator system, the data needs to be normalized as follows:

$$
\begin{gathered}
X_{i j}^{\prime}=\frac{X_{i j}-\overline{X_{j}}}{\sigma_{x j}}, \\
Y_{i j}^{\prime}=\frac{Y_{i j}-\overline{Y_{j}}}{\sigma_{y j}},
\end{gathered}
$$

where $X_{i j}$ and $Y_{i j}$ are the observed values of the $i$ th index. However, according to sustainable development theory, negative effects on subsystems are generated by indicators reflecting low productivity and environmental pollution in $X_{i}$ and $Y_{i}$, which should be treated positively. According to the existing research experience, we conduct five indicators which contain C7, E2, E4, E5, and E6 in SE and EE subsystems to be treated positively after normalization; thus, we obtain the normalized datasets $X_{i j}^{\prime}$ and $Y_{i j}^{\prime}$.

3.3. Evaluation of the Weights of Indicators in SE and EE Subsystems. In terms of evaluation weights of the subsystems, the principal component analysis (PCA) is applied on SE subsystem dataset $X_{i j}^{\prime}$ and EE subsystem data set $Y_{i j}^{\prime}$. According to the eigenvectors and the eigenroot $\lambda_{i}$ of the correlation coefficient matrix $R$, the principal components of the correlation coefficient matrix $R$ can be obtained. If the variance contribution rate in which the principal component corresponds to $\sum_{i=1}^{m} p_{i} \geq 85 \%$, we can obtain the comprehensive developmental level value $X$ of SE subsystem and $Y$ of EE subsystem by applying the former $m$ main component values $F_{i}$ and the corresponding weight $p_{i}^{\prime}=\lambda_{i} / \sum_{i=1}^{m} \lambda_{i}$.

3.4. Calculation of the Static Coupling Degree. The calculation method of the static coupling degree which refers to the coupling status between the SE subsystem and EE subsystem in each year is adopted for reference of Sang et al. [26] and $\mathrm{Li}$ et al. [24]. $X$ and $Y$ represent the comprehensive developmental level of the SE subsystem and EE subsystem, respectively. Regarding $X$ as the dependent variable and $Y$ as the independent variable, we can obtain relative comprehensive development index of EE to $\mathrm{SE} X^{\prime}$ by regression; similarly, regarding $Y$ as the dependent variable and $X$ as the independent variable, we can obtain relative comprehensive development index of SE to EE $Y^{\prime}$. Thus, the static coupling degree can be calculated as

$$
C_{s}(i, j)=\frac{\min \{u(i / j), u(j / i)\}}{\max \{u(i / j), u(j / i)\}}
$$

where $C_{s}(i, j)$ is the static coupling degree, $u(i / j)$ is the adaptability of EE to SE, and $u(i / j)$ is the adaptability of SE to $\mathrm{EE}$, in which the adaptability can be calculated in the following equation:

$$
\begin{aligned}
& u(i / j)=\exp \left[-\frac{\left(X-X^{\prime}\right)^{2}}{S_{x}^{2}}\right], \\
& u(j / i)=\exp \left[-\frac{\left(Y-Y^{\prime}\right)^{2}}{S_{y}^{2}}\right],
\end{aligned}
$$

where $S_{x}^{2}$ and $S_{y}^{2}$ are the mean variances of the comprehensive developmental level of the SE subsystem and EE subsystem, respectively.

3.5. Calculation of the Dynamic Coupling Degree. According to the calculating method of coupling degree by Sang et al. [26] and $\mathrm{Li}$ et al. [24], the dynamic coupling degree can be calculated in the following equation: 
TABLE 1: Evaluating indicator system of SE and EE subsystems.

\begin{tabular}{|c|c|c|c|}
\hline Subsystem & Area & $\begin{array}{c}\text { Indicator } \\
\text { code }\end{array}$ & Indicator \\
\hline \multirow[t]{10}{*}{ Social economy subsystem } & \multirow{6}{*}{ Economic scale } & $\mathrm{C} 1$ & Per capita GDP \\
\hline & & $\mathrm{C} 2$ & Economic density \\
\hline & & $\mathrm{C} 3$ & Per capita income \\
\hline & & $\mathrm{C} 4$ & Per capita trade volume \\
\hline & & $\mathrm{C} 5$ & Per capita investment in fixed assets \\
\hline & & C6 & Per capita retail sales of consumer goods \\
\hline & \multirow{2}{*}{ Economic structure } & $\mathrm{C} 7$ & The proportion of output value of primary industry \\
\hline & & $\mathrm{C} 8$ & The proportion of output value of tertiary industry \\
\hline & Economic & $\mathrm{C} 9$ & Average salary of employees \\
\hline & performance & $\mathrm{C} 10$ & Social labor productivity \\
\hline \multirow{11}{*}{$\begin{array}{l}\text { Ecological environment } \\
\text { subsystem }\end{array}$} & \multirow{3}{*}{ Resource level } & E1 & Per capita water resources \\
\hline & & $\mathrm{E} 2$ & GDP energy consumption per ten thousand yuan (RMB) per capita \\
\hline & & E3 & forest stocking volume \\
\hline & $\begin{array}{l}\text { Environmental } \\
\text { pollution }\end{array}$ & $\mathrm{E} 4$ & Per capita $\mathrm{SO}_{2}$ emission \\
\hline & \multirow{4}{*}{$\begin{array}{c}\text { Environmental } \\
\text { pollution }\end{array}$} & E5 & Per capita COD emission \\
\hline & & E6 & Per capita solid waste emission \\
\hline & & E7 & The proportion of environmental investment in GDP \\
\hline & & E8 & Comprehensive utilization of industrial solid waste \\
\hline & $\begin{array}{l}\text { Environmental } \\
\text { protection }\end{array}$ & E9 & Standard-reaching rate of industrial wastewater emission \\
\hline & Environmental & E10 & Standard-reaching rate of industrial dust emission \\
\hline & protection & E11 & Standard-reaching rate of industrial $\mathrm{SO}_{2}$ emission \\
\hline
\end{tabular}

$$
C_{d}(t)=\frac{1}{T} \sum_{i=0}^{T-1} C_{s}(t-i), \quad 0<C_{d}(t) \leq 1,
$$

where $C_{S}(t-T+1), C_{S}(t-T+2), \ldots, C_{S}(t-1), C_{s}(t)$ are the static coupling degrees of each year in the period $(t-T)-t$. Dynamic coupling degree represents the coupling status of the subsystems in a period of time, which can reflect the coupling development trend compared to static coupling degree.

3.6. Calculation of the Coupling Coordination Degree. As an important index measuring the coupling relation between $\mathrm{SE}$ and EE, there is a limit of the coupling degree that it cannot reveal the developmental function and comprehensive benefit of SE and EE subsystems. For instance, an uncoordinated situation may contain a high coupling degree, but the developmental level of SE and EE subsystems is relatively low. Thus, we apply the coupling coordination degree $D$ which measures the developmental level of subsystems calculated in the following equations:

$$
\begin{aligned}
& D=\sqrt{C_{s} \cdot T}, \\
& T=\alpha f(x)+\beta g(y),
\end{aligned}
$$

where $C_{s}$ is the static coupling degree and $T$ is the evaluation index reflecting the comprehensive developmental level of SE and EE subsystems. $\alpha$ and $\beta$ are undetermined weights, due to the fact that equal importance of the social economy and the ecological environment is assessed; thus, $\alpha=\beta=0.5$.

\section{Analysis of Coupling Coordination Degree in Northeastern China}

4.1. Data Specification. On the basis of the indicator system of SE subsystem and EE subsystem, data related to Northeastern provinces including Heilongjiang, Jilin, and Liaoning is considered from 1990 to 2019. Data of indicators is obtained from Statistical Yearbook and Environmental Protection Bulletin 1991-2020, including Heilongjiang Statistical Yearbook, Heilongjiang Environmental Protection Bulletin, Jilin Statistical Yearbook, Jilin Environmental Protection Bulletin, Liaoning Statistical Yearbook, and Liaoning Environmental Protection Bulletin. The values of indicators in Northeastern China are summed with data of the three Northeastern provinces. However, data of "the $\mathrm{SO}_{2}$ removal rate" indicator is incomplete due to changes in statistical methods in the Statistical Yearbook; we estimate the $\mathrm{SO}_{2}$ removal value by "sulfur dioxide emissions from waste gas" and "waste gas removal rate" drawn from the calculation method of Chen [27] considering the technological process of sulfur dioxide emissions.

4.2. Evaluation of CCDM of SE and EE Subsystems in Northeastern China. In this study, the raw data of SE and EE subsystem indicators is normalized with the Z-score method and treated positively by SPSS software. The comprehensive developmental levels of SE and EE subsystems in Northeastern China are calculated with the method on the basis of principal component analysis, as shown in Figure 1.

As described in Section 3.4, datasets $X^{\prime}$ and $Y^{\prime}$ are obtained by regression analysis of the comprehensive 


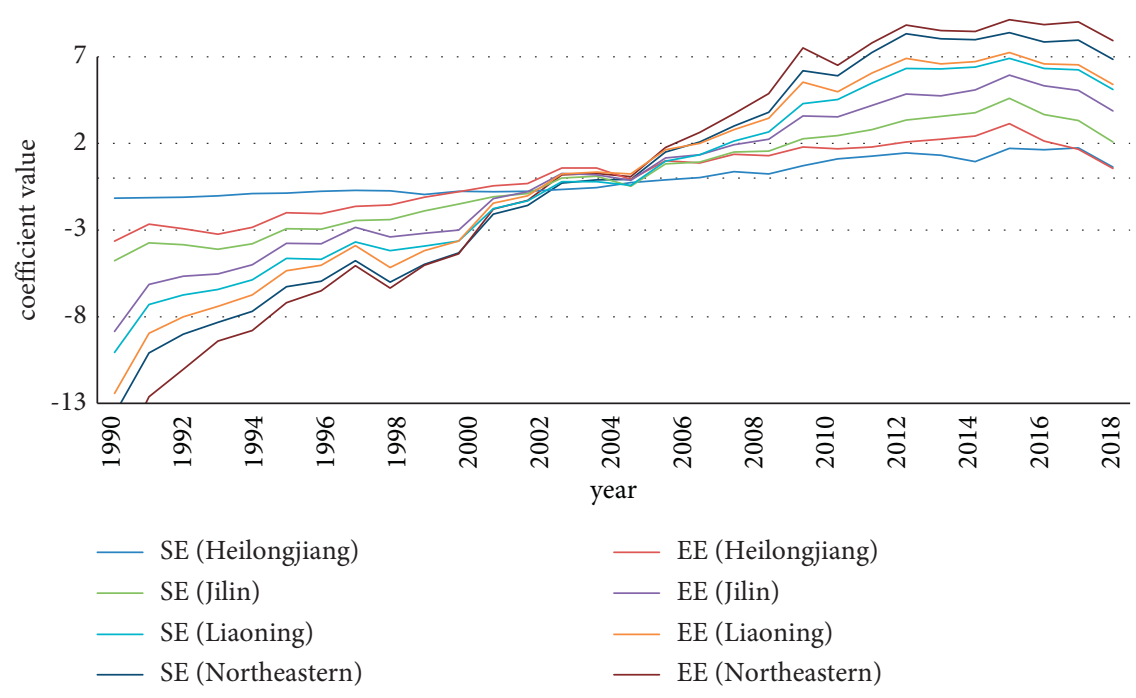

FIgURE 1: Comprehensive developmental levels of SE and EE subsystems in Northeastern China from 1990 to 2019.

developmental level of SE and EE subsystems in Northeastern China. The static coupling degree, dynamic coupling degree, and the coupling coordination degree are calculated with the method described in Sections 3.4-3.6, as shown in Figure 2 .

\subsection{Analysis of Coupling Coordination Development in Northeastern China}

4.3.1. Analysis of Coupling Coordination Degree in Northeastern China. As shown in Figure 2 which reveals the static coupling degree (SCD), dynamic coupling degree (DCD), and the coupling coordination degree (CCD) in Northeastern China, the overall trends of SCD and CCD which witnessed three inverted $U$ fluctuation tend to be similar. The overall trend of DCD was consistently increasing from 1990 to 2019. Due to the empirical results and comparison with existing literature, three findings are obtained. (1) From 1990 to 2019, SCD, DCD, and CCD in Northeastern China's fluctuation increased, which indicated that the coordination of SE and EE is gradually optimized in recent years. The interaction between SE and EE in Northeastern China has significantly enhanced, which implies that marketization reform unleashed economic vitality and improved the quality of the ecological environment since the reform and opening-up. (2) Three peak points that revealed good coordination with CCD values over 0.8 were observed in 1995, 2010, and 2017, which coincides with the implementation time of important policies in Northeastern China, e.g., the market-oriented reform of state-owned enterprises (1995), the revitalization of the old industrial base (2010), and the new rejuvenation of Northeastern China (2017). It may indicate that the coupling coordination of SE and EE in Northeastern China is more susceptible to macroregional policies. (3) The average level of SCD, DCD, and CCD (0.496, $0.513,0.349)$ reveals that the sustainable development in Northeastern China is tiny coordination according to the classification standard by Li et al. [8], which is consistent with varies of research literature [13, 28, 29]. Compared with the existing empirical level of coupling coordination degree of Eastern China, Central China, and Western China in other literature studies, there exist gaps regarding coordination of SE and EE between Northeastern China and other regions $[7,13]$. Combined with the comprehensive developmental levels of SE and EE in Figure 1, it indicates that the reason for low coordination from 1990 to 2006 is the relatively low level of EE, while the coordination level decreased from 2007 to 2019 due to the relatively low level of SE, which implies that Northeastern China has gained economic growth due to dividends from reform and opening-up but meanwhile sacrificed the ecological environment quality in the process of economic development. To sum up, the level of coupling coordination degree in Northeastern China indicates that sustainable development is still primary, which would hinder sustainable transition in the future.

4.3.2. Heterogeneity Analysis on Coupling Coordination Degree of Three Provinces in Northeastern China. Due to the heterogeneous economic structure and growth pattern in different provinces in Northeastern China, there exists an imbalance of coupling coordination degrees in three provinces. We further evaluate the SCD, DCD, and CCD of each province of Heilongjiang, Liaoning, and Jilin to analyze their heterogeneous characteristics. The empirical results adopted by CCDM are shown in Figure 3.

Consistent with that of Northeastern China, SCD, DCD, and CCD revealed fluctuating increases from 1990 to 2019, while imbalance appeared among the three provinces. In terms of SCD, values of Heilongjiang province and Liaoning province are presented at a relatively high level which lied in a highly coupling state, while values of Jilin province displayed a tiny coordinated state in most years presenting an opposite fluctuating state. The overall fluctuating trend in Liaoning displayed a similar trend with that in Northeastern 


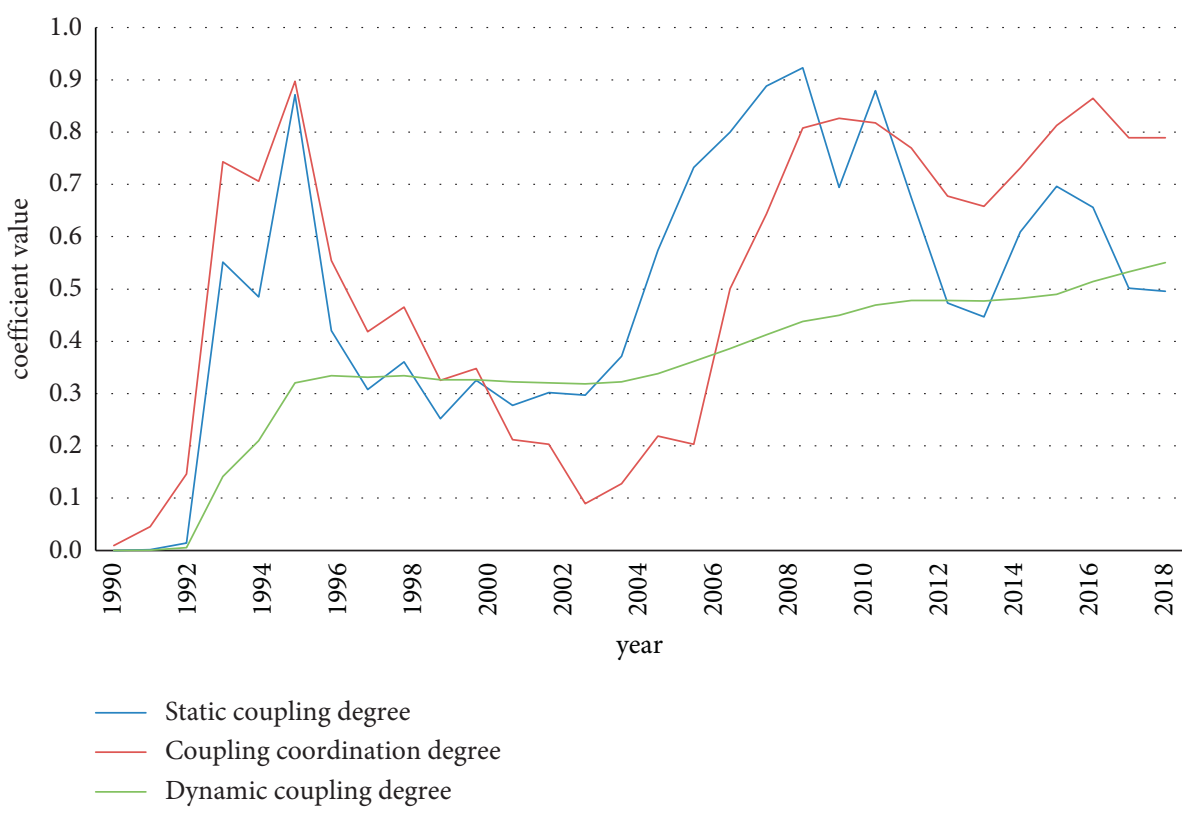

FIgURE 2: Static coupling degree, dynamic coupling degree, and the coupling coordination degree between SE and EE in Northeastern China, 1990-2019.

China except for the increasing trend in current years of 2015-2019. By contrast, the first inflection point of Jilin province was delayed in the year 1997 compared with that of Northeastern China (1994), and in recent years (2011-2019), a similar decreasing trend occurred. The trends of SCD in three provinces implied that intense change of the SCD values of Liaoning province and Jilin province affected the overall trend in Northeastern China, while values of Heilongjiang province displayed a consistent trend with a relatively high coupling state different from that in Northeastern China.

In terms of DCD values of three provinces in Northeastern China, results shown in Figure 2 implied that overall trends of the DCD in three provinces appeared to display an obviously stable curve with an unsatisfied primary coordinated state less than 0.6 , indicating that the DDC degree of Northeastern China since 2011 obviously affected the declining trends of Jilin province and Liaoning province.

In terms of CCD which measures the developmental level of the regional economy and ecological environment shown in Figure 2, levels of CCD in Heilongjiang province presented a significant decline of less than 0.6 since 2017, although the SCD and DCD displayed in relatively good condition, which denoted that the relation of SE and EE in Heilongjiang province was manifested as a high coupling but low developmental status. Values of CCD in Jilin province achieved rapid growth as well as a strong fluctuation among the three provinces since 2005, indicating a great potential of sustainable development, while it lacked momentum due to the declining trend after 2011. Contribution to the improvement of developmental level in SE and EE subsystems was expected on the basis of the overall trend of CCD in Heilongjiang province and Liaoning province after 2014.

\section{Impact of Marketization on Coordination of SE and EE}

5.1. Measurement and Empirical Design of Marketization. Empirical results within values of SCD, DCD, and CCD in Northeastern China displayed a moderate sustainable developmental level but a tiny coordinated state in recent years, which indicated that the coupling relation of SE and EE should be focused on in future development. As mentioned in Section 2.2, various previous research studies argued that pollution behavior was restricted by general economic laws as a kind of economic behavior [30]. Marketization provided an influence on the relation between SE and EE with the false information on the scarcity of resources released by prices [31]. As an old industrial base and a traditional resourcebased region, a limited development occurred in Northeastern China due to system problems. Since the implementation of the revitalization strategy in Northeastern China, the important purpose of the reform was to improve the effect of marketization. The empirical study of the effect of marketization on coupling coordination degree is expected to provide a new way beneficial for coupling development between the economy and the environment through the market mechanism.

According to the internationally accepted standards of economic liberalization, marketization is defined as the liberalization of economic resource allocation and individual economic rights through a series of gradual changes in economic, social, and legal systems. Referring to the NERI INDEX of Marketization, the measurement of marketization is borrowed from the method of Fan et al. [23], Yan [32], and Fan et al. [12]; we construct the index system of marketization as shown in Table 2.

Due to the changes in statistical indicators in the Statistical Yearbook, it is difficult to obtain data of some indicators, we 

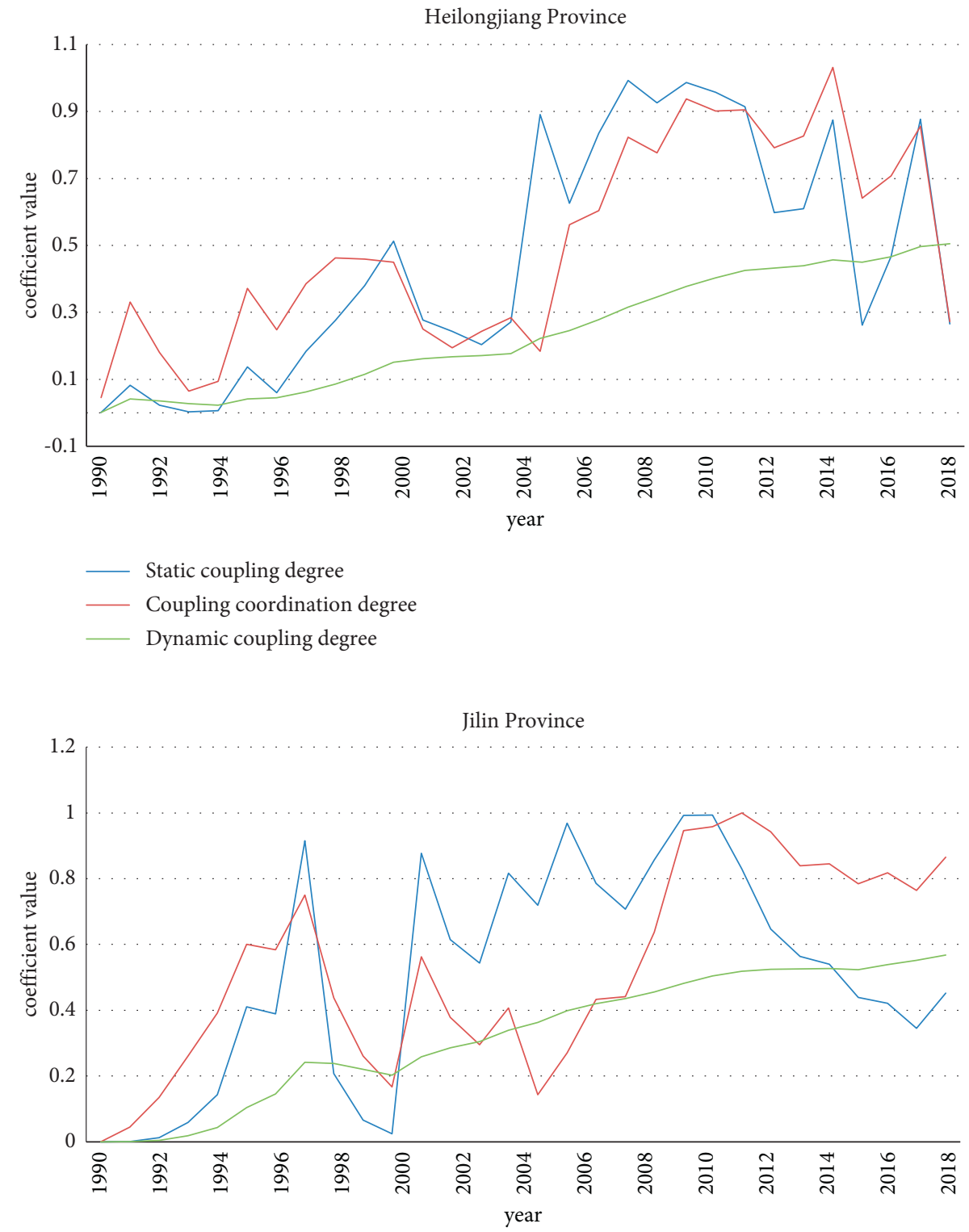

Static coupling degree

Coupling coordination degree

Dynamic coupling degree

(a)

Figure 3: Continued. 


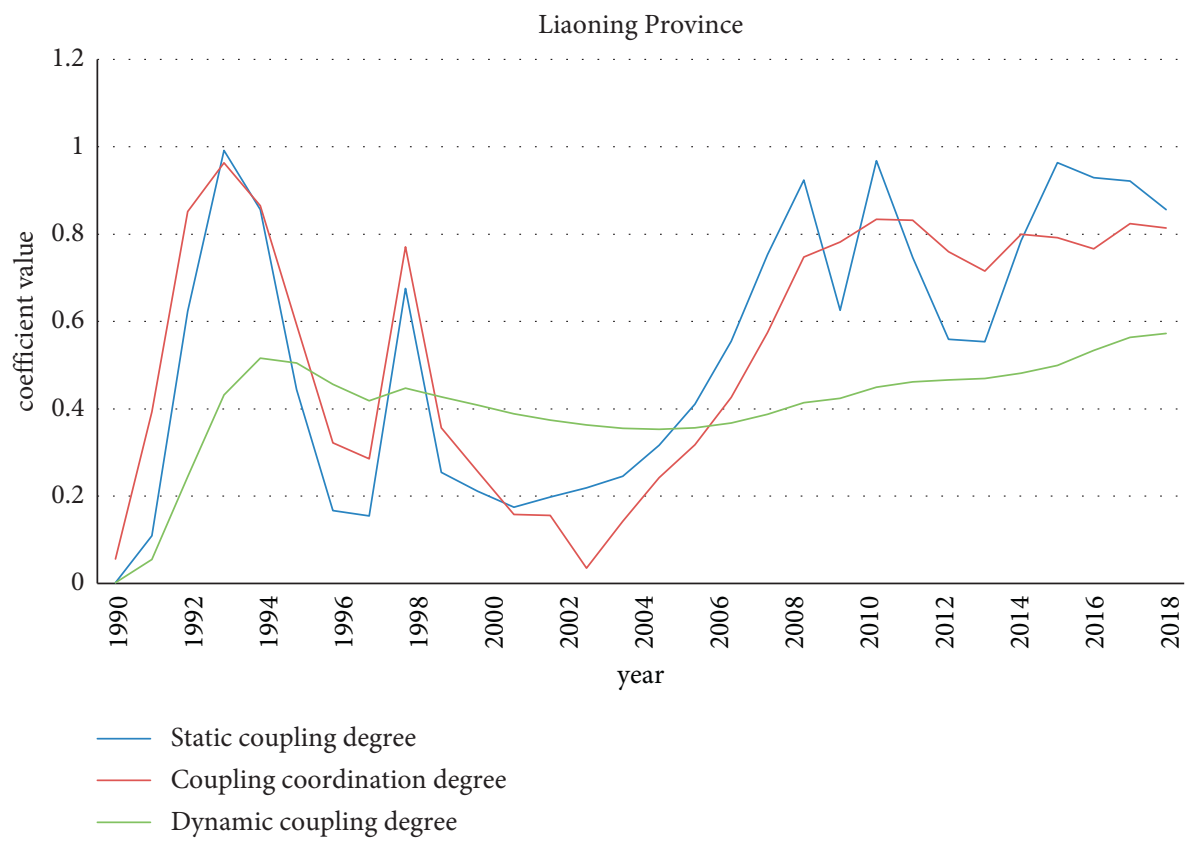

(b)

FIGURE 3: Static coupling degree, dynamic coupling degree, and the coupling coordination degree between SE and EE in each province, 1990-2019.

TABLE 2: Index system of marketization.

\begin{tabular}{|c|c|c|}
\hline First-grade indexes & Secondary indexes (weights) & Index definition \\
\hline \multirow{2}{*}{$\begin{array}{l}\text { Standardization of } \\
\text { government conduct }\end{array}$} & $\begin{array}{l}\text { M1 Government consumption } \\
(-0.0754)\end{array}$ & $\begin{array}{l}\text { The proportion of the annual fiscal expenditure of nonmarket profit- } \\
\text { making institutions funded by the government to GDP }\end{array}$ \\
\hline & M2 Size of government (0.1144) & $\begin{array}{l}\text { The proportion of the number of state workers and staff members in } \\
\text { state organs, party and government organs, and public organizations }\end{array}$ \\
\hline \multirow{3}{*}{$\begin{array}{l}\text { Liberalization of economic } \\
\text { subjects }\end{array}$} & $\begin{array}{l}\text { M3 Investment in nonstate fixed } \\
\text { assets }(0.115)\end{array}$ & $\begin{array}{l}\text { The proportion of nonstate-owned fixed assets investment in the } \\
\text { whole society fixed assets investment }\end{array}$ \\
\hline & $\begin{array}{l}\text { M4 Scale of personnel in nonstate- } \\
\text { owned units }(0.1281)\end{array}$ & $\begin{array}{l}\text { The proportion of nonstate institutions in cities and towns workers in } \\
\text { urban professionals }\end{array}$ \\
\hline & $\begin{array}{l}\text { M5 Output value of nonstate } \\
\text { economy and industry }(0.1052)\end{array}$ & $\begin{array}{c}\text { The proportion of industrial output value of nonstate economy in } \\
\text { total industrial output value }\end{array}$ \\
\hline \multirow{3}{*}{$\begin{array}{l}\text { Marketization of key } \\
\text { resources }\end{array}$} & $\begin{array}{l}\text { M6 Labor autonomy in } \\
\text { occupational selection }(0.1253)\end{array}$ & $\begin{array}{c}\text { The index weighted average of the proportion of individual } \\
\text { employment in employment and the proportion of nonagricultural } \\
\text { employment in rural employment }\end{array}$ \\
\hline & $\begin{array}{l}\text { M7 Marketization of credit } \\
\text { allocation }(0.1064)\end{array}$ & The proportion of nonstate bank loans to total loans \\
\hline & $\begin{array}{l}\text { M8 Marketization of technical } \\
\text { elements }(0.132)\end{array}$ & The proportion of technical market turnover to technical personnel \\
\hline \multirow{2}{*}{$\begin{array}{l}\text { Perfection of the market } \\
\text { system }\end{array}$} & $\begin{array}{l}\text { M9 Scale of market intermediary } \\
\text { personnel }(0.118)\end{array}$ & The proportion of financial insurance to real estat \\
\hline & $\begin{array}{l}\text { M10 Degree of intellectual property } \\
\text { protection }(0.1311)\end{array}$ & $\begin{array}{l}\text { The proportion of the number of authorized patents to the number of } \\
\text { scientific and technological workers }\end{array}$ \\
\hline
\end{tabular}

collect data of marketization indicators from 1994 to 2019 from the Statistical Yearbook, Financial Yearbook, and Labor Yearbook 1987 to 2020 of three provinces in Northeastern China. Z-score normalization is conducted with the raw data and the principal component analysis was used to evaluate the weights of each indicator. In terms of the weights of indicators through principal component analysis, primary indicators including "scale of personnel in nonstate-owned units," "labor autonomy in the occupational selection," "marketization of technical elements," and "degree of intellectual property protection" affected the level of marketization, which indicated that the development of human capital mobility and innovation activity influenced marketization as well as economic development. The overall trend of the marketization index in Northeastern China displayed fluctuant and ascending from 1994 to 2019 with a significantly increasing posture after 2006. In order to verify the impact of marketization on SCD, DCD, and CCD in Northeastern China, the Eviews 9.0 software was 
TABLE 3: Results of ARMA regression of marketization index and the coupling coordination degrees.

\begin{tabular}{lccc}
\hline & SCD & DCD & CCD \\
\hline Constant term & $0.4797^{* * *}$ & -0.4281 & -1.0433 \\
$M$ & $-0.3337(-1.5467)$ & $0.0485(0.3078)$ & $-0.3302^{* *}(-1.9876)$ \\
$\operatorname{lnGDP}$ & $1.2786^{* *}(2.5087)$ & $0.158^{*}(1.9458)$ & $1.5088^{* *}(2.5756)$ \\
$\operatorname{lnFDI}$ & $-0.5409^{*}(-1.9078)$ & $-0.0508(-0.3156)$ & $-0.815^{* * *}(-4.0584)$ \\
AR $(1)$ & $0.3984^{*}$ & $0.843^{* * *}$ & $0.4298^{*}$ \\
SigmaSQ & $0.0217^{* *}$ & $0.0011^{* * *}$ & $0.0183^{* *}$ \\
\hline
\end{tabular}

Note: the symbols ${ }^{* * *},{ }^{* *}$, and ${ }^{*}$ indicate the significance level of $1 \%, 5 \%$, and $10 \%$, respectively.

adopted to establish the ARMA regression model with a fixed effect. We put the marketization index as the independent variable and coupling coordination degrees as the dependent variable. In order to reflect the change of economic development environment since the market-oriented reform, regional GDP and regional foreign direct investment (FDI) were added as control variables. The empirical regressive model lies as follows:

$$
\begin{aligned}
& \ln \mathrm{SCD}=c+\beta_{1} \ln M+\beta_{2} \ln \mathrm{GDP}+\beta_{3} \ln \mathrm{GDP}+\mu, \\
& \ln \mathrm{DCD}=c+\beta_{1} \ln M+\beta_{2} \ln \mathrm{GDP}+\beta_{3} \ln \mathrm{GDP}+\mu, \\
& \ln \mathrm{CCD}=c+\beta_{1} \ln M+\beta_{2} \ln \mathrm{GDP}+\beta_{3} \ln \mathrm{GDP}+\mu .
\end{aligned}
$$

\subsection{Analysis and Discussion regarding the Impact of Marketization}

5.2.1. Analysis of Empirical Results. The regression analysis results shown in Table 3 presented that there was no significant relation between the marketization index and SCD nor DCD in Northeastern China expect for a significant negative correlation of the marketization index and CCD under the confidence interval of $10 \%$, which indicated that long-term sustainable development of SE and EE rather than the interaction between SE and EE in Northeastern China is related to marketization. The negative coefficient of marketization on CCD indicates that marketization hinders the coordination development in Northeastern China, which is consistent with the theory of the Environment Kuznets Curve (EKC). In the early stages of economic development, gradually advanced marketization releases regional economic vitality with an extensive form, which boosts economic growth at the expense of the ecological environment. Thus, there exists an imbalance between SE and EE, leading to the decline of CCD in Northeastern China. In terms of the control variables of GDP and FDI, the empirical results show that the coefficients of GDP in three models all present significantly positive with SCD, DCD, and CCD, which verifies the applicability of scale economy effect in Northeastern China. With the improvement of economic development, the regional economic environment will be more coordinated. Meanwhile, the coefficients of FDI show an opposite impact compacted with those of GDP, which may reveal the existence of the pollution shelter phenomenon. As a representative resource-based region and backward region, the introduction of highly polluting technologies in international trade practices damaged the ecological environment in Northeastern China, leading to unsatisfied coordination of SE and EE.

5.2.2. Further Discussion regarding the Impact of Marketization. Our findings regarding the impact of marketization on the coordination development in Northeastern China demonstrate that marketization only negatively affects the coordination development of SE and EE rather than their coupling degree while coefficients of SCD and DCD show nonsignificant with marketization, which implies that marketization can only affect the development level of SE and $\mathrm{EE}$ rather than their interactions. We attempt to conduct a further discussion regarding this impact of marketization. Compared with studies of Chen et al. [13] and Su et al. [7], our empirical results have reached a consensus on the significant impact of marketization on economic systems, which are supported by various researches. With the growth of the social economy, the interaction with the ecological environment will become more and more obvious. Meanwhile, there will exist certain social norms in a maturing market economy, resulting in the behavioral norms (e.g., environmentally friendly behaviors) by which people restrict themselves, which links marketization and the interaction of $\mathrm{SE}$ and EE. However, the degree of marketization in Northeastern China may be not mature enough compared with other regions of China, which indicates that ecofriendly social norms may not yet be formed in the current economic system, which may be the reason for the nonsignificant relationship between marketization and coordination development of SE and EE.

\section{Conclusion and Policy Suggestions}

In this paper, we conducted an empirical study of the impact of marketization on the coordinated relation between the social economy (SE) and the ecological environment (EE) adopting the coupling coordination degree model (CCDM) with the case of Northeastern China in order to verify the issue that whether marketization would affect the sustainable development. Our findings are shown in the following aspects. First, regarding the levels of sustainable development, the results indicated that the average values of the static coupling degree (SCD), dynamic coupling degree (DCD), and coupling coordination degree (CCD) remained in a tiny coordinated state, which indicated that the level of sustainable development in Northeastern China was presented still primary from 1990 to 2019. Second, coordination 
development of three provinces in Northeastern China presented heterogeneous conditions. Jilin province displayed a relatively low developmental level but a high coupling level, while Heilongjiang province and Liaoning province had a similar trend with that of Northeastern China. Third, to answer the issue that whether marketization can affect the coupling coordination which measures the situation of sustainable development, a marketization index is constructed to verify the impact of marketization on coupling coordination degree in Northeastern China from 1994 to 2019. The results indicated that a significant negative correlation between marketization and CCD was verified under the confidence interval of $10 \%$. The ascending marketization index under policy reform could hinder the coordination development of SE and EE to some extent in Northeastern China.

In order to further play the important role of marketization on coordination development and promote sustainable development in Northeastern China, we propose the following policy suggestions. First, with the development of the economy, Northeastern China should pay attention to the coordinated development of the social economy and ecological environment. As a resourcebased region, Northeastern China has been negatively affected by the resource curse in recent years. Thus, Northeastern China needs to pay attention to the negative externalities brought by the ecological environment. Second, due to the significant role of marketization on the coordination between SE and EE, Northeast China needs to consistently advance the market-oriented reform in order to release the positive externality of marketization to regional sustainable development. The improvement of the marketization degree is conducive to the formation and perfection of environmentally friendly social norms, which would link marketization and the coupling interaction relationship between social economy and ecological environment.

\section{Abbreviation}

SE: Social economy

EE: Ecological environment

SCD: Static coupling degree

DCD: Dynamic coupling degree

CCD: Coupling coordination degree.

\section{Data Availability}

Data were obtained from the China Statistical Yearbook, China Labor Statistics Yearbook, and the Statistical Yearbook of each province.

\section{Disclosure}

The funding sponsors had no role in the design of the study; in the collection, analyses, or interpretation of data; in the writing of the manuscript; and in the decision to publish the results.

\section{Conflicts of Interest}

The authors declare no conflicts of interest.

\section{Authors' Contributions}

Sai Tang and Yue Zhu designed the framework of this paper; Yue Zhu and Fang Wang collected available data and developed the data analysis; Yue Zhu guided the whole process of writing; Sai Tang, Yue Zhu, and Na Shen jointly wrote this paper.

\section{Acknowledgments}

This work was supported by the National Social Science Fund of China under (Grant number: 19BJY153).

\section{References}

[1] M. Ma, W. Cai, and W. Cai, "Carbon abatement in China's commercial building sector: a bottom-up measurement model based on Kaya-LMDI methods," Energy, vol. 165, pp. 350368, 2018.

[2] M. Ma, X. Ma, W. Cai, and W. Cai, "Carbon-dioxide mitigation in the residential building sector: a household scalebased assessment," Energy Conversion and Management, vol. 198, Article ID 111915, 2019.

[3] M. Ma, X. Ma, W. Cai, and W. Cai, "Low carbon roadmap of residential building sector in China: historical mitigation and prospective peak," Applied Energy, vol. 273, Article ID 115247, 2020.

[4] Y. Weng, W. Cai, and C. Wang, "Evaluating the use of BECCS and afforestation under China's carbon-neutral target for 2060," Applied Energy, vol. 299, Article ID 117263, 2021.

[5] G. Roland, Transition and Economics: Politics, Markets and Firms, MIT Press, Cambridge, MA, USA, 2000.

[6] K. Wang, B. Zhao, L. Ding, and Z. Miao, "Government intervention, market development, and pollution emission efficiency: evidence from China," The Science of the Total Environment, vol. 757, Article ID 143738, 2020.

[7] X. Su, X. Yang, J. Zhang et al., "Analysis of the impacts of economic growth targets and marketization on energy efficiency: evidence from China," Sustainability, vol. 13, no. 8, p. 4393, 2021.

[8] W. Li, P. Yi, D. Zhang, and Y. Zhou, "Assessment of coordinated development between social economy and ecological environment: case study of resource-based cities in Northeastern China," Sustainable Cities and Society, vol. 59, Article ID 102208, 2020.

[9] B. Peng, X. Sheng, and G. Wei, "Does environmental protection promote economic development? From the perspective of coupling coordination between environmental protection and economic development," Environmental Science and Pollution Research, vol. 27, no. 31, pp. 39135-39148, 2020.

[10] M. Xu, C. Chen, and X. Deng, "Systematic analysis of the coordination degree of China's economy-ecological environment system and its influencing factor," Environmental Science and Pollution Research, vol. 26, pp. 29722-29735, 2020.

[11] X. Yan, M. Chen, and M.-Y. Chen, "Coupling and coordination development of Australian energy, economy, and 
ecological environment systems from 2007 to 2016," Sustainability, vol. 11, no. 23, p. 6568, 2019.

[12] G. Fan, G. Ma, and X. Wang, "Institutional reform and economic growth of China: 40-year progress toward marketization," Acta Oeconomica, vol. 69, no. s1, pp. 7-20, 2019.

[13] T. Chen, H. Lu, R. Chen, and L. Wu, "The impact of marketization on sustainable economic growth-evidence from west China," Sustainability, vol. 13, no. 7, p. 3745, 2021.

[14] C. Wang and Y. Liu, "A review on the harmony of economy and environment research," China Population, Resources and Environment, vol. 12, no. 3, pp. 32-36, 2002, in Chinese.

[15] L. Ma, F. Jin, Z. Song, and Y. Liu, "Spatial coupling analysis of regional economic development and environmental pollution in China," Journal of Geographical Sciences, vol. 23, no. 3, pp. 525-537, 2013.

[16] R. Kamran and F. S. Reza, "Measuring eco-efficiency based on green indicators and potentials in energy saving and undesirable output abatement," Energy Economics, vol. 50, pp. 18-26, 2015.

[17] T. Li, Y. Han, Y. Li, Z. Lu, and P. Zhao, "Urgency, development stage and coordination degree analysis to support differentiation management of water pollution emission control and economic development in the eastern coastal area of China," Ecological Indicators, vol. 71, pp. 406-415, 2016.

[18] Y. Zhao, S. Wang, and C. Zhou, "Understanding the relation between urbanization and the eco-environment in China's Yangtze River Delta using an improved EKC model and coupling analysis," The Science of the Total Environment, vol. 571, pp. 862-875, 2016.

[19] G. Grossman and A. Krueger, Environmental Impacts of a North American Free Trade Agreement, NBER Working Paper Series, Cambridge, MA, USA, 1991.

[20] J. Huang, X. Yang, and Y. Hu, "The source of incoordination and coordination of resources, economy and environment system: based on a new framework (CREE-EIE)," China Industrial Economics, vol. 7, pp. 17-30, 2014, in Chinese.

[21] K. Dong, X. Dong, and Q. Jiang, "How renewable energy consumption lower global $\mathrm{CO}_{2}$ emissions? Evidence from countries with different income levels," The World Economy, vol. 43, no. 6, pp. 1665-1698, 2019.

[22] D. North, Institutions, Institutional Change and Economic Performance, Cambridge University Press, Cambridge, UK, 1990.

[23] G. Fan, X. Wang, L. Zhang, and H. Zhu, "Marketization index for China's provinces," Economic Research Journal, vol. 3, pp. 9-18, 2003, in Chinese.

[24] Y. Li, Z. Zeng, Y. Wu, and Y. Li, "Study and application of evaluation method of coordinated development of economyenvironment system," Systems Engineering-Theory \& Practice, vol. 5, pp. 54-58, 2003, in Chinese.

[25] F. Tan and Z. Lu, "Study on the interaction and relation of society, economy and environment based on PCA-VAR model: as a case study of the Bohai Rim region, China," Ecological Indicators, vol. 48, pp. 31-40, 2015.

[26] Q. Sang, P. Zhang, F. Su, and X. Xin, "Coordination degree of urban population, economy, space and environment in Shenyang since the 1990s," China Population, Resources and Environment, vol. 18, no. 2, pp. 115-119, 2008, in Chinese.

[27] S. Chen and T. Chen, "Air pollution and public health: evidence from sulfur dioxide emission of coal-fired power stations in China," Economic Research Journal, vol. 8, pp. 158-169, 2014, in Chinese.

[28] N. Ning, "Evaluation on coordination degree between environmental and economic development in Baotou city,"
Journal of Arid Land Resources \& Environment, vol. 22, no. 1, pp. 32-35, 2008.

[29] L. Zhang, Y. Xu, C.-H. Yeh, Y. Liu, and D. Zhou, "City sustainability evaluation using multi-criteria decision making with objective weights of interdependent criteria," Journal of Cleaner Production, vol. 131, pp. 491-499, 2016.

[30] G. Xia and H. Qin, "An analysis on the economic mechanism of the enterprise's pollution actions," China Environmental Science, vol. 9, pp. 241-246, 1989, in Chinese.

[31] J. Stiglitz, "Growth with exhaustive natural resource: efficient and optimal growth paths," The Review of Economic Studies, vol. 41, pp. 29-45, 1986.

[32] D. Yan, "Innovative evaluation instrument on marketization and evaluation for China's regional characteristics of marketization (2000-2005)," Journal of Finance and Economics, vol. 33 , no. 8 , pp. 41-50, 2007, in Chinese. 